\title{
The Implementation of Knowledge Strategy-Based Entrepreneurial Capacity to Achieve Sustainable Competitive Advantage
}

\author{
Widodo \\ Faculty of Economics, Sultan Agung Islamic University
}

\begin{tabular}{l|l}
\hline ART ICLE INFO ABSTRACT \\
\hline
\end{tabular}

Keywords:

Innovativeness,

Proactive,

Risk-taking,

knowledge strategy,

sustainable competitive advantage
This study aims to develop a model of knowledge strategy-based entrepreneurial capacity to achieve sustainable competitive advantage of rurol banking in Central Java province. The sampling method is "Purposive sampling" by considering the characteristics of the population items, namely: operational experience for at least 5 years and representatives of each area of rurol banking in Semarang, Surakarta and Purwokerto. Then, the sample size is 150 of $251(59.7 \%)$ of top managers of rurol banking. To analyze the data in this study, it used the Structural Equation Modeling (SEM), of the, AMOS software package. The findings of this study explain that 1). The first step in promoting a sustainable competitive advantage through knowledge sharing is by prioritizing the quality of interaction, willingness and ability. 2). Efforts to improve a sustainable competitive advantage through knowledge exploitation built by knowledge sharing are by prioritizing to actively accept changes and introduction, solve problems together, use and combine new knowledge in operation. 3). Efforts to improve a sustainable competitive advantage through the knowledge exploitation built by risk-taking are by prioritizing a strong tendency for high-risk projects (with the possibility of gaining high-return), a high courage for the actions necessary to achieve the goal, having an aggressive attitude to optimize the possibility of utilizing existing potential opportunities and enjoying the challenge of the risk situation. 4). Efforts to improve a sustainable competitive advantage through knowledge exploitation built by a pro-active are by prioritizing to anticipate problem more quickly than competitors, future oriented, addressed by technology, launching product selectively and systematically search for new ideas. 5). Efforts to improve a sustainable competitive advantage through knowledge exploitation built by the innovativeness are by prioritizing the speed of developing products, the implementation of new technology and market development. 


\section{INTRODUCTION}

A sustainable competitive advantage has an important role to create new knowledge that is useful in constant. Therefore, knowledge management is a management of all processes involving knowledge. There are some perspectives in knowledge management involving how knowledge is created, developed and reused in business environment, or how it is formulated and implemented through knowledge strategy. However, many studies on knowledge strategy are conducted separately. In addition, it focuses on policy knowledge within the companies, as it is done by Alberto F (2011) which is only theoretical and merely related to organizational context. Therefore, the knowledge strategy can be further developed in enhancing entrepreneurship.

In addition to the implementation of knowledge strategy, there is a prerequisite to be fulfilled by an organization in order to be success in business, namely entrepreneurial capacity (Saowaluk Jitnom, 2009). The Phenomenon of entrepreneurial capacity is a driving force for organization in entrepreneurial activities and becomes focus on central entrepreneurial research (Jeffrey G. Covin and William J. Wales, 2012). Entrepreneurial capacity reflects the tendency of companies to be innovative, pro-active and risk-taking (Gregory \& Lumpkin. D: 2005). The concept of entrepreneurial capacity is focused on the ability to understand entrepreneurial activities within organization. Yet, it has not received more attention to be studied even though it is important to be involved (Jeffrey G. Covin and William J. Wales, 2012).

The study by Widodo (2011) shows that average of 6 of 10 rurol banking in Central Java province belongs to local government. The involvement of bureaucracy to bring its culture, as manager of a limited entrepreneurial capacity, is not able to bring rurol banking into a good professional matter. This phenomenon becomes a reason why there is still a high level of risk above the maximum limit of 5\%. Moreover, most of the rurol banking are not optimized to develop new products to improve their innovative competitiveness with the larger financial institutions and other Microfinance Institutions (MFIs). Based on the explanation above, it can be concluded that to manage organization is actually to manage knowledge. A good knowledge is implemented not only limited to information, but also more. Therefore, this study aims to formulate a model of knowledge strategy based on entrepreneurial capacity to achieve sustainable competitive advantage.

\section{Literature Review \\ Entrepreneurial Capacity}

Entrepreneurship refers to behavior which includes initiative and creative thinking, social and economic organization to change resources and receive risk of failure (Verena C. Hahn et al: 2012). Meanwhile, according to Cardon, Wincent, Singh, \& Drnovsek, (2009), entrepreneurship is characterized by high-motives to work, long hours of working, and high passion and proactive. The main quality of entrepreneurship is a new entry, which is entering new market segment by launching new products and old products. Then, it is associated with the power of innovation referring to the scope of the companies that support new fresh ideas, experimentation, and creative processes to invent new products and techniques.

There is a prerequisite to be fulfilled by an organization in order to be success in business, namely entrepreneurial capacity (Saowaluk Jitnom, 2009). The Phenomenon of entrepreneurial capacity becomes a driving force for organization in entrepreneurial activities which has been a focus on central entrepreneurial research (Jeffrey G. Covin and William J. Wales, 2012). Entrepreneurial capacity reflects the tendency of companies to be innovative, pro-active and risktaking (Gregory \& Lumpkin. D: 2005). In detail, this can be explained as follows:

\section{a. Proactive}

Study by Lumkin \& Dess (1996) explains that being 
a proactive entrepreneur is the willingness to reactpositively, identify opportunities, dominate competitors through a combination of proactive and aggressive measures, future oriented, introduce newp roducts or services, and anticipate demands or complaints to create changes and environmental influences. The attitude of proactive entrepreneur is marked with anticipatory, future orientation or change-oriented, persistent and active working attitude (Frank D. Belschak and Deanne N. Den Hartog, 2010). Meanwhile, according to Astha Sharma and Suniita Dave (2011), it is characterized by taking initiative to anticipate and seek new market opportunities. Furthermore, a proactive entrepreneur attitude also related to approach which encourages organizations to obtain product launch as soon as possible as way to generate funds quickly or obtain rapid market feedback (GT Lumpkin, Keith H. Brighamb and Todd W. Moss: 2010). Therefore, to respond to external dynamics, companies need to consistently transfer its entrepreneurial orientation so as to become a strategic activity that practically meet corporate goals and simultaneously achieve its superior performance by focusing on the process of creating knowledge within the company.

\section{b. Risk Taking}

Risks are associated with the possibility of loss or adverse consequences which potentially interfere with the ability of an organization to achieve its goals and fulfill its mission. Risks to achieve goals can arise both from internal and external activities A good risk management must be able to provide solution for organization, as a tool to improve management strategy, operations and even finances. Besides that, it can also minimize the losses of financial, service disruption, declining publicity, public health threats and compensation claims (Mario J. Donate and J. Ignacio Canales: 2010). Meanwhile, a study by Gregory G. Dess (2005) explains that risk taking is associated with the willingness of organizations to take advantage of business opportunities despite not knowing its succes and failure. Therefore, to be success through entrepreneurship, a company usually takes an alternative risk. For instance, to gain high financial income, a company sometimes takes high level of debt, add more resources and introduce new products to the market.

Risk taking is regarded as characteristics of entrepreneurial behavior, though many previous studies show that many entrepreneurs do not see their actions as a risk taking (Lumpkin, 2010). Furthermore, it also explains that the family company takes a less risk than non-family. A more risk-taking organization will be able to make strategic decisions faster, and as its consequences, they can increase the level of overall performance (Covin and Slevin, 1989; Eisenhardt, 2000).

\section{c. Innovation}

The knowledge-based perspective explains that innovation is essentially seen as a process to produce new idea and implement it in a way that produces value (Tatiana Andreeva and Aino Kianto, 2011). Innovation reflects company's tendency to cope with new ideas and creative processes to produce new products, services or process of technology. Therefore, innovation is a creative solution to face challenges and opportunities of company. Innovation is very important to small and medium enterprises (SMEs) due to the fact that SMEs still have some limits to compete in the form of financial, human resources, economies scale and reputation. Therefore, SMEs need to show their superior performance through innovation.

The role of innovation in entrepreneurship is as a crucial factor to facilitate growth, to offer new products with high potential profit, and to increase the overall market value. The discovery of a unique approach to technology, product and process, in turn, will develop special abilities (Patrick M. Kreiser, 2013). A study by Jahangir Yadollahi (2013) explains that innovation is one of the key factors to achieve sustainable competitive advantage and long-term success in a competitive market because the innovation can 
respond environmental challenges faster than non-innovative ones. This, in turn, can increase organizational efficiency. Moreover, Innovation includes all new ideas, methods, or goals of organization which are successfully implemented in the market. Innovation figures out openness, acquiring and obtaining new ideas and tendency of changes through new technology, resources, skills, and administration system.

Based on the literature review, there are three aspects of innovation, namely productive, administrative, and process of innovation (Jimenez and Valle, 2011). 1) Productive innovation is a tool for production and refers to the development of new products and services. In fact, productive innovation is the extent to which an organization becomes proactive in providing new services and allocating financial resources for research and development. 2) The process of innovation is a tool to maintain and improve the quality and lower the cost. This includes new or integrated production, distribution methods, or delivery. The process of innovation is the extent to which an organization using new technologies and testing new methods to accomplish organizational task. 3) Administrative innovation refers to procedures, policies, and new organizational forms. This includes changes that affect policy, resource allocation, and other factors related to social organization structures. In other hand, it relates with the extent to which managers can use modern management system to manage their organization.

\section{d. Knowledge Strategy}

Relevance of knowledge assets as a basis for strategic factors in the success of the business has been widely recognized in today's competitive scenario (Barney, 1991). In fact, there are a growing number of organizational competitions in the ownership of knowledge assets and considering knowledge to be a competitive differentiator in the knowledge of economy (Nonaka \& Takeuchi, 1995). Such environmental conditions have become a strategic aspect to the success and priority of competition. Therefore, a strategy basically can be defined as a plan designed to achieve a long term goal.

Based on the study of Alberto F. De Toni (2011), Knowledge strategy includes: 1). Knowledge sharing as a behavior to disseminate knowledge with other members in an organization so as to create value-added for the company, 2). Knowledge Exploitation which acquires competence by adopting, synthesizing and applying existing knowledge to be manipulated and improved. Briefly, this can be explained as follows:

\section{a. Knowledge Sharing}

The study by Reed, Srinivasan and Doty (2009) explains that knowledge sharing is the interaction and communication between individuals and business units. The success of knowledge sharing depends on the quantity and quality of interaction among employees and the willingness and ability to use knowledge. Organizations should encourage both employee and organization's goals, and then define these goals into technical and promotion of employees. Existing knowledge within the individual is difficult to verbalize, therefore, it needs to be articulated and expressed implicitly.

Based on the explanation above, it can be concluded that knowledge sharing is the behavior of a person to disseminate knowledge with other members in an organization so as to create value- added for the company. Emphasis on the knowledge will trigger the development of the concept of Knowledge Management (KM) by the assumption that the knowledge of the inputs influences the production process. In detail, KM empasizes on the company's ability to use and combine a variety of knowledge resources to turn intangible resources into a product or process of innovation (Grant, 1996).

Knowledge sharing occurs at the individual 
and organizational level. At the individual level, knowledge sharing is done through discussions with fellow employees to assist them to work better, faster and more efficiently. Whereas at the level of the organization, knowledge sharing is an attempt to capture, manage, reuse, and transfer knowledge-based experiences within the organization and make it available to others in the business. Numerous studies have shown that knowledge sharing is very important because it enables organizations to improve innovation performance and reduce the excessive cost of learning (Lin, Hsiu Fen 2010). A company can successfully increase the culture of knowledge sharing not only by combining knowledge in business strategy directly, but also by changing attitude and behavior of employees to be willing and consistent to encourage knowledge sharing.

Wang (2011) argues that the practice of knowledge sharing throughout the organization is very important to maintain the company's values, to learn new techniques, to solve problems faced by the company, to create competence core and to initiate new situation. Knowledge sharing will change organizational knowledge into individual or group knowledge through internalization and socialization process. Otherwise, knowledge sharing can interpret individual and group knowledge into knowledge organizations based on the process of externalization and combinations. Face-to-face interaction is the primary means in the process of tacit knowledge sharing.

Gagne (2005) identifies several important factors infuencing knowledge sharing. It is identified that there are individual factors influence it, such as the presence of distrust, fear of loss of power, and lack of social networks. Moreover, another factor influencing knowledge sharing is the organizational factors that include lack of leadership, precise system of rewards and opportunities to share knowledge. In addition, technological factors, such as incorrect use of information and technology systems and the lack of training activities, can affect knowledge sharing. The success in the implementation of knowledge sharing depends on the attitude of employees towards knowledge sharing itself.

The study by Chung-Jen Chen (2010) explains that in a successful innovation exists a new combination of knowledge by forming association among new existing knowledge. The creation of knowledge is effective to increase new association by providing opportunities for companies to recombine for the new generation of knowledge. Innovations facilitate the development of new organizational routines and inventions of unique approach to technology, products and processes, which in turn it can develop special abilities (Patrick M. Kreiser, 2013). Consequently, it is strived to capture, manage, reuse and transfer knowledge-based experience within the organization and make it available for others in the business or knowledge sharing (Lin, Hsiu-fen, 2007). Therefore, the first hypothesis proposed is:

H1: the higher the intensity of innovativeness is, the higher the intensity of knowledge sharing will be.

Prerequisite of successful organizations in business requires entrepreneurial orientation. Phenomenon of entrepreneurship has become a driving force in the organization of activities and focus of entrepreneurial research (Jeffrey G. Covin William J. Wales. 2012). Entrepreneurial orientation reflects the tendency of companies to be innovative (Lumpkin. D \&Covin, 1997). Proactive is a tendency of someone to start a change in any situations. Proactive individuals are dynamic agents that identify and utilize opportunities to bring changes in the environment as well as create the new ones. Proactive individuals tend to be future-oriented and persist with their activity until the goal is reached. Conversely, low-proactive individuals tend to be relatively passive, accept things as they are, and shaped by the environment. Hence, Proactive 
positively influences employees' behavior and work attitudes because individuals tend to proactively identify and create opportunities to bring favorable conditions for individual or team (Gary J. Gregorus: 2010).

The main quality of entrepreneurship is new entry identified by entering a new market segment with the launch of new products and the old ones. Innovation power refers to the scope of the enterprise supporting fresh ideas, experimentation and creative processes to produce new products and techniques. Entrepreneurship is characterized by high motive and more hours to work and marked with full passion and proactive (Cardon, Wincent, Singh, \& Drnovsek: 2009).

The success in the implementation of knowledge sharing depends on the attitude of entrepreneurs (Gagne: 2005). Proactive entrepreneur attitudes are marked with anticipation, future or changeoriented, persistent and active working (Frank D. Belschak and Deanne N. Den Hartog. 2010). Meanwhile, according to Astha Sharma and Suniita Dave (2011) it is characterized by taking initiative through anticipating and seeking new market opportunities. The attitude knowledge sharing is formed with positive beliefs to share knowledge with other members in organization. Therefore, the second hypothesis is:

$\mathrm{H} 2$ : the higher the intensity of pro-activeness is, the higher the intensity of knowledge sharing will be

Risk taking is regarded as characteristics of entrepreneurial behavior, though previous research shows that many entrepreneurs do not see their actions as a risk (GT Lumpkin, 2010). The Study by Gregory G. Dess, (2005) explains that taking a risk is not speculative because the organization investigates consequences of opportunities and creating possible scenarios to achieve goals by the purpose to reduce risk of decision-making business. There are two methods used to strengthen the competitive position through risk taking, they are: 1). Researching and assessing risk factors to minimize uncertainty, and 2). Implementing the other tried-and-true techniques.

Knowledge sharing is one of important components of knowledge management, a successful and efficient knowledge sharing can facilitate the creation of new knowledge and help a company to maintain performance (Qian Huang, Robert M. Davison \& Jibao Gu, 2011). Knowledge sharing creates opportunities to optimize organizational capability and generate solutions and efficiency. As a result, it makes business ready to face sustainable competitive advantage (Lin Hsiu Fen, 2007). Therefore we need a selective process.

The process of knowledge sharing related to how the human resources within the organization share work-experience, skills, know-how, and information with other colleagues. The process of knowledge sharing can be understood as process through which human resources have mutual exchange of knowledge and create new knowledge together. Knowledge sharing involves both good supply and demand of new knowledge. The interaction among individuals is the primary means in the process of knowledge sharing. Beside that, the focus of knowledge sharing is on the willingness and the capacity of individuals to share what they know and use what they learn (Lin Hsiu Fen, 2007). While Wang (2012) explains that the experience of individuals in self-employment or entrepreneurial capacity is the basis of knowledge sharing. Therefore, the third hypothesis proposed in this study is:

H3: the higher the intensity of risk-taking is, the higher the intensity of knowledge sharing will be

\section{a. Knowledge exploitation}

Exploitation is basically process of acquiring competence through adopting, synthesizing and applying existing knowledge. This requires 
knowledge createdand internalized for used and create reliable experience (Weiping Liu, 2006). Exploitation refers to the application of external knowledge to improve existing products and process (Paul E. Bierly (2009).

Jun $\mathrm{Li}$ and Weihe Gao (2013) conclude that exploitation strategy offers advantages to entrepreneurs. First, exploitation is a means to fully utilize limited resources in technology and existing domain market products. Companies learn it efficiently from local and nearby sources. Moreover, Chung-Jen Chen (2010) explains that during the period of developing new product, innovation will motivate human resources to take risks for challenging and finding creative idea of knowledge to invent new products. Human resources tend not only to exchange and share knowledge for the creative mind, but also look for newest thing and different approach to work. In other words, the human resources are more likely to integrate new knowledge generated. Therefore, the fourth hypothesis proposed in this study is:

H4: the higher the intensity of innovativeness is, the higher the intensity of knowledge exploitation will be

The main role for knowledge exploitation aims to create or increase the output (Juan Gabriel Cegarra-Navarro, 2011). Knowledge exploitation is learning activities of utilizing available resources (Weiping Liu, 2006). To fulfill such condition, it is necessary to possess proactive human resources. Proactive attitude is the entrepreneurial approach which encourages company to get new product launch as soon as possible as way to generate funds quickly or obtain rapid market feedback (GT Lumpkin, Keith H. Brighamb and Todd W. Moss, 2010). Therefore, the fifth hypothesis is:

H5: the higher the intensity of proactiveness is, then the higher the intensity of knowledge exploitation will be
A study by Gregory G. Dess (2005) explains that dare to take risk (risk taking) is related to the willingness of the organization to take advantage of business opportunities despite not knowing whether the business will be success or not and act without regarding any consequences. Consequently, exploiting human knowledge are more likely to integrate new knowledge possessed by organization (Chung-Jen Chen, 2010). Therefore, the sixth hypothesis proposed in this study is:

$\mathrm{H6}$ : the higher the intensity of the risk-taking is, the higher the intensity of knowledge exploitation will be

Based on the literature review, knowledge sharing is the behavior of a person to disseminate knowledge with other members in an organization so as to create value-added for the company. Rifat Kamas and Fusun Bulutlar (2010) explain that the dissemination and responsiveness to knowledge or knowledge sharing is the two most important components because nature is unique. Consequently, it will collect and integrate knowledge ceaselessly. Therefore, the seventh hypothesis proposed in this study is:

H7: the higher the intensity of knowledge sharing is, the higher the intensity of knowledge exploitation will be

\section{Sustainable Competitive Advantage}

Study by Mukesh Srivastava, Andy Franklin, Louis Martinette (2013) concludes that dimensions of sustainable competitive advantage involve durability, immitability and ease to match strategic assets of the company. Knowledge organization represented by knowledge, culture, routines and experiences, and generate added value for the customer and for the scarcity of competitors will create a competitive advantage (Barney, 1991). Therefore, the eighth hypothesis proposed hypothesis in this study is: 
H8: the higher the intensity of knowledge sharing is, the higher the sustainable competitive advantage will be

Exploitation of knowledge is basically a process to acquire competence through adopting, synthesizing and applyingexisting knowledge. This requires knowledge which has been created and internalized for used and create reliable experience (Weiping Liu, 2006). Recently, there are many organizations consider new knowledge to becoming deference so as to obtain a sustainable competitive advantage. In such environment, knowledge exploitation will be a strategic aspect for the success and priority of competition (Nonaka \& Takeuchi, 1995). Therefore, the hypothesis ninth hypothesis proposed in this study is:

H9: the higher the intensity of knowledge exploitation is, the higher the sustainable competitive advantage will be

Based on the literature review with in-depth and comprehensive explanation above, the empirical research model is presented in Figure 1.

\section{METHODS}

\section{Respondents}

The population in this study is all leaders of rurol banking in Central Java Province, amounting to
251. This study uses the Maximum Likelihood model estimation (ML). The sample size is 100 200 (Imam Gozali, 2004). Hair et.al (1996) state that the sample size is total number of indicators multiplied by 5 to 10 . Therefore, the number of samples in this study is 150 (59.7\%) respondents. The sampling method uses purposive sampling by taking into account on the characteristics of the population, namely: a). Operational experience for at least 5 years, .b). Representatives of Bank Indonesia regional office in Semarang, Surakarta and Purwokerto.

\section{Sources and Data Collection Techniques}

The data source of this study include: 1). Primary data, the data is obtained directly from the respondent that is the manager of rurol banking in Central Java Province. This data is taken based on a questionnaire distributed to respondents. Moreover, the primary data in this study are the respondents answer on the study variables. 2) Secondary Data, it is the data that has been processed by the person or institution and has been published. The data are obtained from Bank Indonesia in 2013, Perbarindo and the literature related to this study.

Then the data collection techniques used in this research is by using a questionnaire, which is a list containing a number of open and closed questions

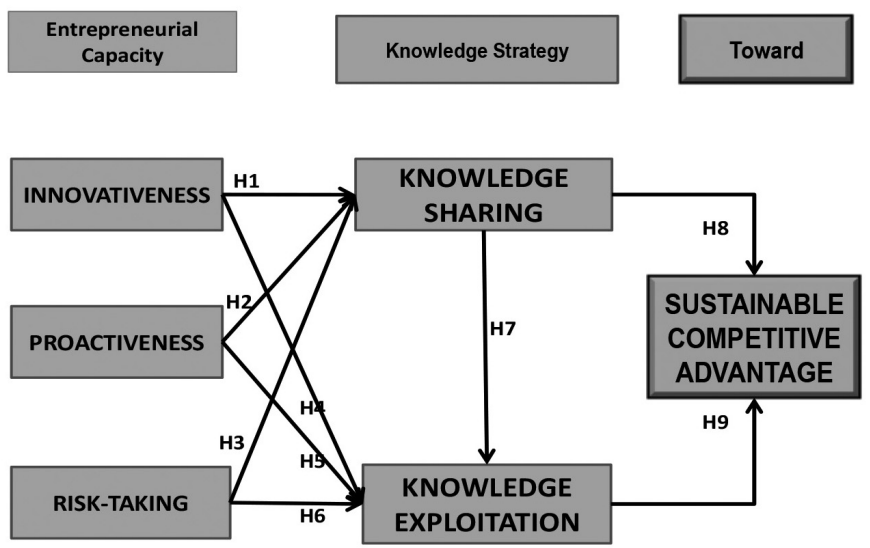

Figure 1. The development model of Knowledge Strategy-based entrepreneurial capacity to achieve Sustainable Competitive Advantage 
to be given to the head of rurol banking in Central Java Province.

\section{Analysis Techniques}

To analyze the data in this study, it uses the Structural Equation Modeling (SEM) of the AMOS software package. This model is a set of statistical techniques that allow the testing of a relatively complex set of correlation (Ferdinand, 2000). The excellence of SEM application in research of management is its ability to confirm the dimensions of a concept or factor and to measure the relationships of existing theories.

\section{RESULTS AND DISCUSSION}

\section{Findings}

Based on the calculations with Structural Equation Model (SEM) with AMOS software, $\mathrm{Cr}$ values or t-test appears in the Table 1.

Table 1 shows that every variable has loading factor value ( $\pi$ coefficient) or regression weight or standardized estimate which is significant to the value of Critical Ratio or $\mathrm{CR} \geq 2.00$. Therefore, the hypotheses proposed can be strengthened by empirical data.

\section{Discussion}

The influence of Innovation toward Knowledge Sharing
The first hypothesis proposed in this study is the higher the intensity of innovativeness is, the higher the intensity of knowledge sharing will be. The finding indicates that in order to improve knowledge sharing, a company should make innovation by indicators of the speed of to product development, application of new technology and market improvement. This finding supports the opinion by Chung-Jen Chen (2010) which explains that a successful innovation requires new combination of knowledge by forming new association among existing knowledge. The creation of knowledge is effective to increase association by providing opportunities for companies to recombine for the new generation of knowledge.

\section{The influence of Pro-activeness toward Knowledge Sharing}

The second hypothesis proposed in this study is the higher the intensity of pro-active is, then the higher the intensity of knowledge sharingwill be. Proactive attitude of an entrepreneur is the disposition to react favorably to identify opportunities, dominate competitors through a combination of proactive and aggressive measures, future-oriented, introduce new products or services, anticipate demands and complaints to create a change to influence surrounding environment. Pro-active is built by indicators of anticipating problems faster than competitors, future-oriented with the trends of

Table 1. Standardized Regresion Weight (Loading Factor)

\begin{tabular}{lccc}
\hline Regression Weights: & Std. Estimate & S.E. & C.R. \\
\hline Knowledge_sharing <---- Risk-Taking & 0.225 & 0.096 & 2.282 \\
Knowledge_sharing <------ Proactive & 0.205 & 0.109 & 2.010 \\
Knowledge_sharing <--- Inovativeness & 0.238 & 0.116 & 2.050 \\
Knowledge_exploitat <- Inovativeness & 0.206 & 0.109 & 2.158 \\
Knowledge_exploitation <-- Proactive & 0.199 & 0.103 & 2.637 \\
Knowledge_exploi <- Knowledge_sharin & 0.249 & 0.101 & 2.053 \\
Knowledge_exploitatio <- Risk-Taking & 0.278 & 0.091 & 3.037 \\
Sustainable_comp <- Knowledge_sharin & 0.216 & 0.126 & 2.061 \\
Sustainable_comp <- Knowledge_exploi & 0.310 & 0.121 & 2.984 \\
\hline
\end{tabular}

Source: AMOS Output 
technology and launching new product selectively, and a systematically search for new ideas. Thus, it will bring initiative to anticipate and search for new market opportunities. The attitude of knowledge sharing is formed with behavioral beliefs and referred to the level of positive or negative aspect of each individual to share knowledge with other members in an organization.

\section{The Influence of Risk-taking toward Knowledge Sharing}

Risk-taking is associated with taking risk that refers to the willingness of the organization to take advantage of the business opportunities despite not knowing whether the business will succeed or not and to act boldly without regarding the consequences. Knowledge sharing processes related to how the human resources within the organization share work-experience, skill, know-how, and information with the other colleagues. The process of knowledge sharing can be understood as a process through which the human resource share knowledge both supply and demand for new knowledge or ideas. The interaction among individuals is the primary means in the process of knowledge sharing. The Focus of knowledge sharing is the willingness and the capacity of individuals to share what they know and use what they learn. On the other hand, individual experience in self-employment or entrepreneurial capacity is the basis of knowledge sharing.

\section{The influence of Innovation toward Knowledge Exploitation}

The fourth hypothesis proposed in this study is the higher the intensity of innovativeness is, the higher the knowledge exploitation will be. The finding indicates that the knowledge exploitation is built with indicators of the speed of product development, application of new technology and market development. The finding supports the notion by Chung-Jen Chen (2010), which explains that during the period of new product development, innovation will motivate human resources to take risks for challenging and finding creative activities of knowledge into new products. Human resources tend not only to exchange and share knowledge for the creative mind, but also look for something new and different approach to work. In other words, the human resources are more likely to integrate new knowledge generated.

\section{The influence of pro-activeness toward knowledge exploitation}

The fifth hypothesis is the higher the intensity of pro-activeness is, the higher the intensity of knowledge exploitation will be. The finding indicates that the variable of knowledge exploitation is formed by indicators of anticipating problems faster than competitors, future-oriented with the trends of technology and launching new product selectively, and a systematically search for new ideas. Moreover, the finding supports the study of Wei Ping Liu (2006) which states that knowledge exploitation is associated with a learning activity to use resources owned. Consequently, it is necessary to have proactive human resources. Proactive stance in an entrepreneurial approach is expected to encourage companies to get a product launch (knowledge exploitation), to generate funds and to obtain feedback as soon as possible (GT Lumpkin, Keith H. Brighamb and Todd W. Moss, 2010).

\section{The Influence of Risk-Taking toward Knowledge Exploitation}

The sixth hypothesis is the higher the intensity of risk-taking is, the higher the knowledge exploitation will be. The finding indicates that the variable of knowledge exploitation is built with indicators of a strong tendency for high-risk projects with the possibility of high return, a high courage of actions to achieve the objectives, possessing aggressive behavior in order to optimize the possibility of utilizing existing potential opportunities and enjoy the challenge of risky situation.

The finding supports the study of Gregory G. Dess (2005) which explains that Risk-taking is associated 
with taking risk that refers to the willingness of the organization to take advantage of the business opportunities and act boldly without considering the consequences. The finding shows that the risk-taking influences knowledge exploitation. Knowledge exploitation can give advantages through increasing efficiency and reducing costs (Alberto F. De Toni, 2011). Therefore, the knowledge exploitation of human resources is more likely to integrate new knowledge generated (Chung-Jen Chen, 2010).

\section{The influence of Knowledge Sharing toward Knowledge Exploitation}

The seventh hypothesis is accepted. The finding indicates that knowledge exploitation is formed with indicators of interaction quality, willingness to share knowledge and ability to share knowledge. This study supports Rifat Kamas and Fusun Bulutlar study (2010) which explains that the dissemination and responsiveness to knowledge or knowledge sharing is the two most important components in organization because of its unique. Consequently, it will continue to collect and integrate knowledge (knowledge exploitation).

\section{The influence of Knowledge Sharing on Sustainable Competitive Advantage}

The eighth hypothesis proposed in this study is the higher the intensity of knowledge sharing is, the higher the intensity of sustainable competitive advantage will be. The finding indicates that sustainable competitive advantage is formed with indicators of interaction quality, willingness to share knowledge and ability to share knowledge. This finding supports opinion of Kogut \& Zander (1996). The view of the knowledge-based organization is started with individuals and companies to become superior in their ability to integrate knowledge across individual/knowledge sharing. Then, Barney (1991) also describes that knowledge organization represented by knowledge, culture, routines and experiences, and generating added value for customers and scarcity to competitors will create a good competitive advantage.
The influence of Knowledge exploitation toward Sustainable Competitive Advantage

The ninth hypothesis proposed in this study is the higher the intensity of knowledge exploitation is, the higher the intensity of sustainable competitive advantage will be. The finding indicates that sustainable competitive advantage is built with indicators to actively accept changes and introduction, solve problems together, exploit knowledge, use and combine valuable knowledge in the operation. Furthermore, this finding supports the idea that nowadays many organizations consider knowledge to become deference so as to obtain a sustainable competitive advantage. In such environment, knowledge exploitation becomes strategic aspects of success and priorities to achieve sustainable competitive advantage (Nonaka \& Takeuchi , 1995).

\section{MANAGERIAL IMPLICATIONS}

A sustainable competitive advantage is essential to the creation of new knowledge which is useful constantly. Therefore, knowledge management is defined as the management of all processes involving knowledge. This thing, furthermore, is related to the formulation and implementation of knowledge strategy which includes knowledge exploitation and knowledge sharing. Prerequisites of successful organization in business require entrepreneurial capacity covering innovativeness, proactiveness and risk-taking. Therefore, to achieve a sustainable competitive advantage in BPR in Central Java with the development of knowledge strategy, the managerial implications are as follows:

Knowledge exploitation, managements actively accept new change and introduction, solve problems together with partners and do activities to gain more experience and better learning of using the knowledge gained.

Knowledge Sharing, managements actively consult with colleagues to learn new things (knowledge collecting). Alternatively, it is as a process of 
consultation and encouragement to other party to share its intellectual, deliver knowledge as means of human resources to actively communicate with others (Knowledge Donating).

Innovation, managements heighten the motivation that affects both knowledge donating and knowledge collecting and lead to have innovation capability to be a superior enterprise. A company that promotes human resources to provide knowledge in groups and organizations is possible to generate new ideas and develop new business opportunities. As a result, it will facilitate innovation activities.

Pro-active, managements continuously monitor changes in the environment. It is done by digging a wide range of relevant information that can be used to improve position. Management may seek for information from informal and personal sources, and relations of power, especially when the environment is changing. If the environment is dynamic and uncertain, leaders are expected to recognize the environment from oral resources. Leaders with strong orientations on the search for and access information are more likely to produce a better strategy formulation. These conditions combined with internal conditions appear in the content strategy that will improve organizational performance.

Risk-Taking, risk management approach should be based on and driven by the goal of organization as in detail it is figured out in the strategy. Strategy and risk management programs should focus on those items to prevent or hinder the achievement of specific objectives in the strategy of the organization. There is a need to start something from a practical, reasonable and solid establishment. Organizations may choose to concentrate at first on a small number of risks which have a major influence and has most likely anyway. Consequently, only a small amount of risk in the beginning that can be identified.

\section{Limitations and Future Research}

Test results with full model of the Structural Equation Model (SEM) show that the model fits the data. However, there are two tests which are marginally accepted, they are the Goodness of Fit Index $(\mathrm{GFI}=0.87)$ and the Adjusted Goodness of Fit Index (AGFI = 0.833).

Organizational culture is an integrated pattern of human behavior and issues related to adjustment or integration of internal and external conditions. Based on the findings of the study, it can be explained that the rurol banking in Central Java province have different characteristics when compared to other provinces RB. This happens because most of rurol banking in Central Java province are owned by local government either district/city or provincial governments. The ownership by local governments needs different treatment with rurol banking owned by individuals or private. Therefore, organizational culture has a role in the process of knowledge strategy as efforts to improve a sustainable competitive advantage. Therefore, further study on organizational culture in the process of developing a sustainable competitive advantage becomes an interesting area of study.

In advanced countries, the trigger to improve sustainable competitive advantage is generally at the dominant source of the internal condition. However, in most developing countries the external condition (environment) is the dominant factors to achieve sustainable competitive advantage. Briefly, Environmental conditions include: 1) Environmental Complexity with the diversity of factors and problems that exist in the organizational environment. 2). Environmental dynamics which illustrate the degree of change that occurs in the environment in which the organization operates. Therefore, the future research agenda needs to be considered.

\section{CONCLUSION}

Based on various significant supports for 
hypotheses testing, it is produced 5 development planning strategy to achieve a sustainable competitive advantage through knowledge strategy based entrepreneurial capacities. 1). The first step in promoting a sustainable competitive advantage through knowledge sharing is by prioritizing the quality of interaction, willingness and ability. 2). Efforts to improve a sustainable competitive advantage through knowledge exploitation built by knowledge sharing are by prioritizing to actively accept changes and introduction, solve problems together, use and combine new knowledge in operatio. 3). Efforts to improve a sustainable competitive advantage through the knowledge exploitation built by risktaking are by prioritizing a strong tendency for high-risk projects (with the possibility of gaining high-return), a high courage for the actions necessary to achieve the goal, having an aggressive attitude to optimize the possibility of utilizing existing potential opportunities and enjoying the challenge of the risky situation. 4). Efforts to improve a sustainable competitive advantage through knowledge exploitation built by a proactive are by prioritizing to anticipate problem more quickly than competitors, future oriented, addressed by technology, launching product selectively and systematically search for new ideas. 5). Efforts to improve a sustainable competitive advantage through knowledge exploitation built by the innovativeness are by prioritizing the speed of developing products, the implementation of new technology and market development.

\section{REFERENCES}

Alberto F. De Toni. Fabio Nonino and Matteo Pivetta. (2011). A Model for Assessing the Coherence of Companies' Knowledge Strategy. Knowledge Management Research \& Practice. 9. 327-341

Astha Sharma and Suniita Dave. (2011). Entrepreneurial Orientation: Performance Level. SCMS Journal of Indian Management, pp.43-52

Barney, J.B. (1991), 'Firm Resources and Sustained Competitive Advantage,' Journal of Management, 17, 99-120.

Bart van den Hooff;de Ridder, Jan A. (2004). Knowledge haring in context: the influence of organizational Journal of Knowledge Management. Volume 8 Nomor (6). pp. 117-130

Cardon, M.S. \& Kirk, C. (2010). Passion and persistence in entrepreneurship. Paper presented at the Academy of Management Conference, Montreal.

Chung-Jen Chen. Jing-Wen Huang. Yung-Chang Hsiao. (2010). Knowledge management andinnovativeness The role of organizational climate and structure. International Journal of Manpower.Vol. 31 No. 8, pp. 848-870

Eisenhardt KM, Martin JK. (2000). Dynamic capabilities:what are they? Strategic Management Journal 21: 1105-1121.

Ferdinand Augusty Tae (2000). Structural Equation Modelling Dalam Penelitian Manajemen . Diponegoro University press.

Frank D. Belschak and Deanne N. Den Hartog. (2010). Pro-self, prosocial, and pro-organizational fociof proactive behaviour: Differential antecedents and consequences. Journal of Occupational and Organizational Psychology, 83, 475-498

Gagn'e M, Deci EL.(2005). Self-determination theory and work motivation. Journal of Organizational Behavior, 26, 331-362.

Gary J. Greguras and James M. Diefenddorff. (2010). Why Does proactive Personality Predict Employee Life satisfaction and Work Behavior? A Field Investigation of The Mediating Role of The Self Concordance Model. Personnel Psychology ,Nomor 63,pp. 539-560

Grant, R.M. (1996). “Toward a knowledge-based theory of the firm”, Strategic Management Journal,Vol. 17, pp. 109-22. 
Gregory G. Dess and Lumpkin. G.T. (2005). The Role of Entrepreneurial Orientation in Stimulating Effective Corporate Entrepreneurship. Academy of Management Executive, 2005, Vol. 19, No. 1

Jahangir Yadollahi . Arash R. Amer Dehghan N.(2013). Social Capital and Organizational Innovation : The Mediating effect of Entrepreneurial Oriention. Journal of Community Positive Practices, XIII(2), pp.22-40.

Jeffrey G. Covin. William J. Wales. (2012). The Measurement of Entrepreneurial Orientation. Enterpreneurship Theory and Practice. 677-702

Jime'nez Daniel Jime’nez and Raquel Sanz-Valle. 2011. Could HRM Support Organizational Innovation?. The International Journal of Human Resource Management,Vol. 19, No. 7, pp.1208-1221

Juan G. Cegarra-Navarro and Frank Dewhurst. (2007). Linking Organizational learningand Customer Capital Through Anambidexterity Context: an empirical investigation in SMEs. International Journal of Human Resource Management. 18:10 .pp.1720-1735

Jun Li and Weihe Gao. (2011). Social Capital, Knowledge Strategy, and New Venture Performance: Evidence From Graduate Entrepreneurial Ventures in China. International Business Administration. 8 (1).pp. 378-383

Lin, Hsiu-Fen. 2007, "A Stage Model of Knowledge Management : an empirical investigation of process and effectiveness", Journal of Information Science, Vol. 33 No. 6, pp. 643-59.

Lin. Hsiu-Fen.(2010). Antecedents of The Stage-Based Knowledge Management Evolution. Journal of Knowledge Management. Vol 15 No.1 pp. 136-155

Lumpkin, G.T. and Dess,C.G. (1997). "Clarifying the entrepreneurial orientation construct and linking it to performance", The Academy of Management Review, Vol. 21 No. 1, pp. 135-72.

Lumpkin. G.T , Keith H. Brighamb and Todd W. Mossb. (2010). Long-term Orientation: Implications for the entrepreneurial orientation and performance of family businesses. Entrepreneurship \& Regional Development. Vol. 22, Nos. 3-4, 241264.

Mario J. Donate and J. Ignacio Canales. (2011). A New Approach to The Concept of Knowledge Strategy. Journal of Knowledge Management. Vol. 16 No. 1, pp. 22-44,

Nonaka, I., and Takeuchi, H. (1995), The Knowledge Creating Company, Oxford: Oxford University Press.

Patrick M. Kreiser . Louis D. Marino, (2013). Disaggregating entrepreneurial orientation: the non-linear impact of innovativeness, proactiveness and risk-taking on SME performance. Small Business Economy. Nomor 40, pp.273-291

Paul E. Bierly III, Fariborz Damanpour and Michael D. Santoro. (2009). The Application of External Knowledge : Organizational Conditions for Explorationand Exploitation. Journal of Management Studies 46 : 3. pp.481-509

Qian Huang, Robert M. Davison* \& Jibao Gu.(2011). The Impact of Trust, Quanxi Orientation and Face on the Intention of Chinese Employees and Managers to Engage in peer-to-peer Tacit and Explicit Knowledge Sharing. Info Systems Journal. Nomor 21, pp. 557-577

Reed, Srinivasan dan Doty. (2009). Adapting Human and Social Capital to ImpactPerformance: Some Empirical Findings from the U.S.Personal Banking Sector. Journal of Managerial issues . Vol 21. Number 1 Spring: pp. 36-57

Rifat Kamas,ak and Fu“sun Bulutlar. 2010. The Influence of Knowledge Sharing on Innovation. European Business Review. Vol. 22 No. 3, pp. 306-317.

Saowaluk Jitno. (2009). Effects of Entrepreneurial Capacity on Business of SMEs in Thailand. Journal International of Business Economics. Volume 9 (1) 1-18

Tatiana Andreeva and Aino Kianto. (2011). Knowledge Processes, Knowledge Intensity and Innovation : a moderated mediation analysis. Journal of Knowledge Management Vol. 15 No. 6. pp. 1016-1034

Mukesh Srivastava, Andy Franklin, Louis Martinette. (2013). Building a Sustainable Competitive Advantage. Journal Technology Management. Innovation. Volume 8, Issue 2.pp.47-60

Verena C. Hahn.Michael Frese.Carmen Binnewies. Antje Schmitt. (2012). Happy and Proactive? The Role of Hedonicand Eudaimonic Well-Being inBusiness Owners'Personal Initiative. Enterpreneurship Theory and Practice. 97-111

Wang, C.L. (2008). "Entrepreneurial Orientation, Learning Orientation, and Firm Performance",Entrepreneurship Theory and Practice, Vol. 32 No. 4, pp. 635-56.

Wang. Catherine L and Levent Altinay. (2011). The influence of anentrepreneur's socio-culturalcharacteristics on theentrepreneurial orientation ofsmall firms. Journal of Small Business andEnterprise Development. Vol. 18 No. 4 , pp. 673-694

Weiping Liu .(2006). Knowledge Exploitation, Knowledge Exploration, and Competency Trap. Knowledge and Process Management. Volume 13 Number 3 pp 144-16

Widodo. (2011). Strategy evaluation rurol banking in Central Java Province. Jurnal Dinamika Sosial Ekonomi, Kopertis Central Java Province. Vol.7.( 2) 113-133 
Appendix

Out put Full Model Strategy Knowledge

64

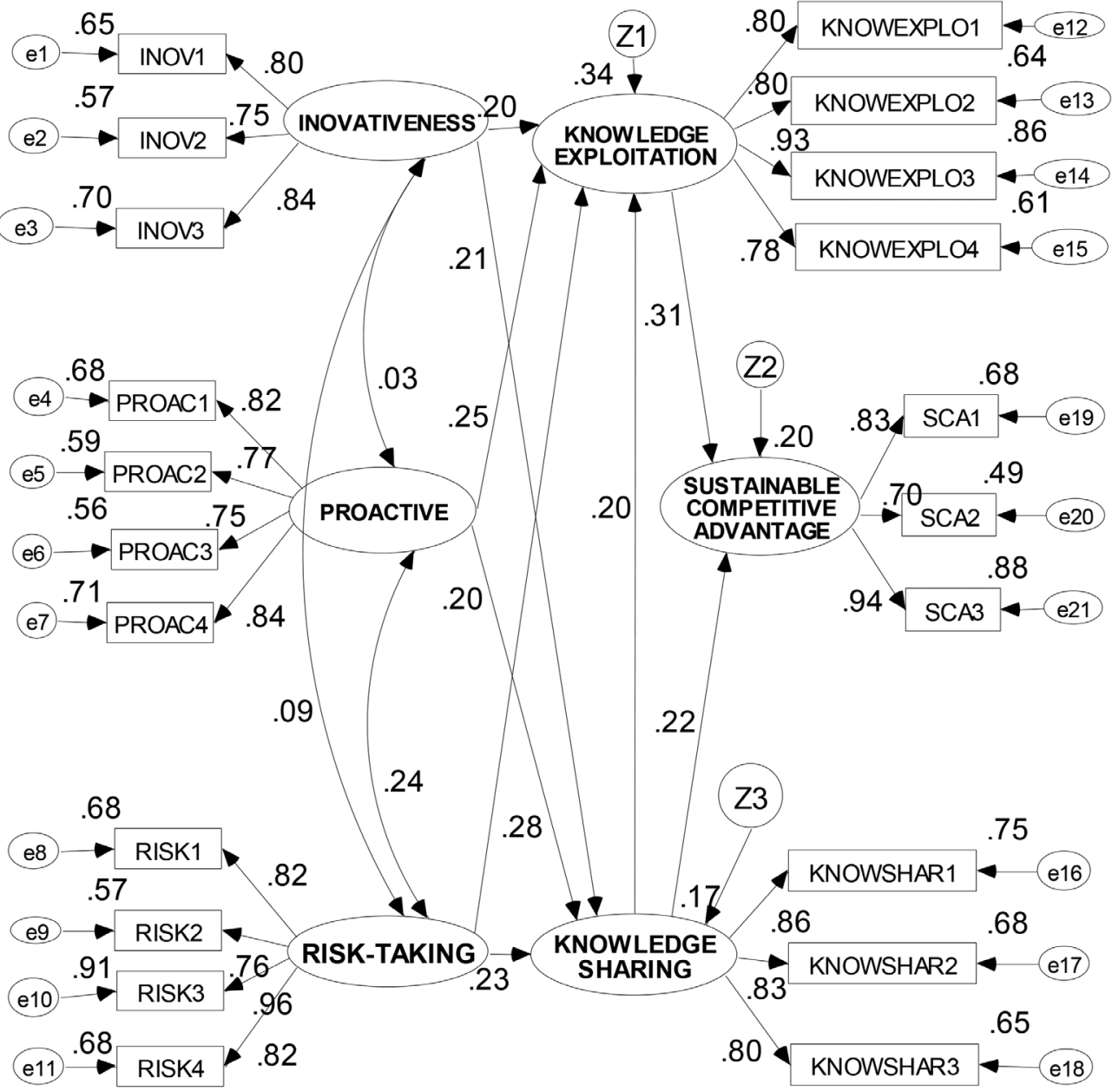

Chi-Square $=192.416(\mathrm{df}=179)$

Probability $=.234$

$\mathrm{CMIN} / \mathrm{DF}=1.075$

$\mathrm{GFI}=870$

$\mathrm{AGFI}=.833$

$\mathrm{TLI}=.989$

$\mathrm{CFI}=.991$

RMSEA $=.025$ 